\title{
Complex habitats may not always benefit prey: linking visual field with reef fish behavior and distribution
}

\author{
G. Rilov ${ }^{1,2, *}$, W. F. Figueira ${ }^{1,3}$, S. J. Lyman ${ }^{1,4}$, L. B. Crowder ${ }^{1}$ \\ ${ }^{1}$ Center for Marine Conservation, Nicholas School of the Environment and Earth Sciences, Duke University, \\ 135 Duke Marine Lab Road, Beaufort, North Carolina 28516, USA
}

${ }^{2}$ Present address: Department of Zoology, Cordley 3029, Oregon State University, Corvallis, Oregon 97331-2914, USA

${ }^{3}$ Present address: Department of Environmental Sciences, University of Technology Sydney, Westbourne St., Gore Hill, New South Wales 2065, Australia

${ }^{4}$ Present address: School of Medicine, University of North Carolina at Chapel Hill, Chapel Hill, North Carolina 27599, USA

\begin{abstract}
Habitat structural complexity is often considered beneficial for prey species because it reduces the foraging efficiency of predators. However, for site-attached, territorial prey, such as many damselfishes, structural complexity at specific scales may be detrimental. Since the location of territorial prey could be highly predictable to predators, the ability of such prey to detect approaching predators may be limited by high-relief structural complexity. The bicolor damselfish Stegastes partitus is abundant and randomly dispersed on coral heads in fore reef habitats in the Florida Keys but is less abundant on back reef habitats, where it aggregates in open patches within fields of gorgonian soft corals. We hypothesized that the complex gorgonian habitat limits the visual field for $S$. partitus, increasing the uncertainty about predation risk, and is therefore a low quality habitat. We found that males occupy territories with visual fields larger than the fields around randomly selected points. Experimentally reducing the visual field around males decreased both their courting rates and the distance they ventured away from the nest. Males in the back reef spent more time away from their nests - potentially taking greater risks - towards the peak of the spawning cycle than males in the fore reef, which may be related to their lower reproductive success on the back reef. Experiments exposing male $S$. partitus to a fish predator suggest that a limited visual field (an uncertain situation) presents a more risky situation than a clearly visible but 'contained' predator. Our results demonstrate that a limited visual field around territorial, site-attached prey fish alters their behavior such that mating and feeding may be compromised. Fish abundance was negatively correlated with soft coral density but not with the number of potential territories or surface rugosity, suggesting that the visual seascape may be important for the fish distribution patterns. We suggest that habitat complexity at the appropriate scale mediates the distribution and possibly also the abundance of territorial prey fishes through the effects of the size of the visual field on fish behavior.
\end{abstract}

KEY WORDS: Seascape $\cdot$ Habitat complexity $\cdot$ Animal distribution $\cdot$ Visual field $\cdot$ Behavior $\cdot$ Fish

\section{INTRODUCTION}

Habitat complexity can differentially affect the distribution of predators and prey. Structure commonly offers refuge for prey and may also increase food availability (Heck \& Crowder 1991). Prey living within sub- merged or emergent macrophytes often use the structural complexity supplied by the plants to avoid predation. Structure can reduce the efficiency of foraging predators by limiting prey detection and predator movement (Crowder \& Cooper 1982, Main 1987, Lindholm et al. 1999, Anderson 2001, Johnson 2006). How- 
ever, structural complexity can also benefit predators. For instance, in aquatic environments, ambush predators can benefit from high structural complexity (e.g. Greenberg et al. 1995) in which they can hide from approaching prey. This may be especially detrimental to relatively sedentary prey species that are also territorial. Such prey species leave their refuge habitat to feed and to interact. Their central location should thus be highly predictable to local predators and the prey thus likely incurs high predation risk when feeding and courting. These species require some habitat complexity for shelter, but should also benefit from having open space around their shelter to detect approaching predators (Karino \& Kuwamura 1997), i.e. a relatively open visual field.

The quality of a habitat is linked to predation risk (e.g. Candolin \& Voigt 2001, Lombardi et al. 2003, Mandelik et al. 2003), and to fitness (Olsson et al. 2002). In the face of persistent risk, reduced activities such as feeding and courtship will eventually manifest in reduced fitness (e.g. breeding suppression, Fuelling \& Halle 2004). If individuals cannot reliably assess local predation risk in order to only exhibit predator avoidance behaviors at appropriate times (e.g. when a predator is present), their fitness potential should decrease (Brown 2003). In this context, structural complexity is clearly linked to the ability to assess predation risk. We suggest that visual field is an important measure of habitat quality for territorial prey, and examine its relationship to behavior and its potential effects on the spatial distribution of prey.

For site-attached, territorial prey species such as damselfish, habitat quality can be assessed at different spatial scales (Sale 1980, Bay et al. 2001), and processes occurring within each will interact to dictate fish distributions. At spatial scales close to that of the size of individual fish, the surface rugosity and the size and shape of holes in the reef determine the quality and abundance of refuge from predators (e.g. Hixon \& Beets 1993, Carr \& Hixon 1995, see Figueira et al. in press). At larger spatial scales, reef relief, complexity and habitat diversity (e.g. substrate types, biogenic structure) will determine the presence of mates, competitors, or predators in an individual's neighborhood. For example, at the scales of $10 \mathrm{~s}$ of $\mathrm{cm}$ to $100 \mathrm{~s}$ of $\mathrm{m}$ the existence of clusters of small areas of suitable habitat, or territories, is required for social interactions and reproduction. At this scale, however, visual obstacles may also impair the size of the visual field and increase the uncertainty of predation risk. At the scale of small reefs, 100 to $1000 \mathrm{~m}$, the type and quantity of different habitats will influence the amount and distribution of fish territories and other resources.

In the lower Florida Keys, off Key West, USA, where we conducted this research, the fore reef seascape is characterized by many small patches of rock or coral surrounded by sand, with most patches occupied by one or several of the ubiquitous Caribbean bicolor damselfish Stegastes partitus (Figueira et al. in press). By contrast, the back reef seascape is characterized by scattered large, mostly horizontal, rocky patch reefs isolated by stretches of sand and seagrass and covered by an almost continuous stand of branching soft corals (gorgonians). While S. partitus are abundant and occur throughout most of the area in the fore reef habitat, on the back reef patches they are less abundant and are tightly aggregated in the open patches within the soft coral fields (Figueira et al. in press). The scarcity of $S$. partitus within denser areas of the gorgonian fields might be due to the reduced visual field. We suggest that areas covered by dense soft corals represent low quality habitats/territories for site-attached territorial fish. Where the cover of tall branching corals is high, the visual field of the fish would be limited, and a species that depends on visual cues to attract mates (the courtship display, e.g. Gronell 1989) and to detect predators (e.g. ambush predators like groupers) might have to compromise its behavior by limiting its movement and courtship activities to reduce predation risk. Choosing (or surviving better in) areas of the reef with fewer visual obstructions may at least partially explain the patchy distribution of $S$. partitus on the patch reefs of the back reef.

Our goal is to test the relationship between the size of the visual field and the behavior of a territorial prey fish, and on the basis of that test, to draw inferences about the distribution and abundance of the species at different habitat types. In this study, we first test the relationships between fish abundance and important aspects of habitat quality that include the visual field, as well as habitat type, amount, and complexity. Because visual field is not necessarily correlated with common measures of habitat complexity, such as rugosity and percent cover, we first develop a methodology to measure the visual field of territorial coral reef damselfish. We then evaluate habitat use relative to the size of the visual field. Finally, we present the results of experiments in which we investigate the potential immediate effects of a reduced visual field on the movement and courtship behavior of male Stegastes partitus.

We make the following predictions: (1) with regard to the measured habitat-complexity, variability of fish abundance will correlate more strongly with soft coral density and height (the habitat's visual environment) than with shelter availability (rugosity), or the availability of potential territory centers (density of high rugosity areas [HRAs]); (2) within each habitat (back and fore reef), fish will be found in areas that have a visual field that is larger than is expected by chance; 
(3) limiting the visual field around the fish will reduce the time males spend away from their nest as well as inhibit their courtship behavior; (4) in the presence of a predator, the intensity and/or frequency of courtship behavior will be reduced when the visual field is limited (due to uncertainty about the predation risk) than when it is not (the predation risk can be more reliably assessed). The predicted immediate effects could have long-term implications on the mortality and fitness of individuals and thus influence fish distribution. We discuss these potential long-term effects and suggest a conceptual model that links seascape to fish behavior and distribution.

\section{MATERIALS AND METHODS}

Study species and sites. Stegastes partitus is a small (<75 mm standard length) sexually monomorphic pomacentrid fish, ubiquitous throughout the Caribbean. Both males and females defend permanent territories in habitats of high rugosity (Myrberg 1972, Schmale 1981) and demonstrate high site fidelity (McGehee 1995). Reproduction follows the lunar cycle, with spawning beginning a few days before the full moon and ending a few days after the new moon (Robertson et al. 1988, Knapp \& Warner 1991). Courting males display vigorously throughout the day; males leave their territories and swim toward females while performing a series of rapid vertical dives termed 'dips' (Myrberg 1972) or 'signal jumps' (Mann \& Lobel 1998), accompanied by a rapid chirp-sound (Myrberg 1997, see Mann \& Lobel 1998). Spawning occurs within a $1 \mathrm{~h}$ period starting at dawn, during which females travel to, and lay eggs in, a nest at the center of the chosen male's territory (Knapp \& Warner 1991). Eggs are demersal and each clutch is laid in a discrete monolayer. Males guard eggs until they hatch as planktonic larvae, $3.5 \mathrm{~d}$ later (Schmale 1981, Robertson et al. 1988). Larvae settle around 5 wk later during the new moon, and recruit mainly to coral rubble. Peak annual settlement occurs around September (McGehee 1995). Adults live on rubble and coral heads. Recruits are benthic feeders, while adults are mainly planktivores feeding up to $1.5 \mathrm{~m}$ above the bottom (Nemeth 1998). S. partitus at all sizes are highly sensitive to predation threat compared to other damselfish (Helfman \& Winkelman 1997, Carr et al. 2002).
Our study was conducted at five $15 \times 15 \mathrm{~m}$ permanent research sites established for multiple studies of Stegastes partitus on the reef just west of the Western Sambos Ecological Reserve, off Key West, Florida, USA (Fig. 1, Figueira 2002 et al. in press). Three sites were located in the platform margin reef habitat on the seaward side of the reef, roughly $15 \mathrm{~km}$ offshore (fore reef sites: FR3, FR4, FR5), and the other 2 were on large patch reefs in Hawk Channel on the leeward side of the reef, roughly $13 \mathrm{~km}$ offshore (back reef sites: BR2, BR3). Establishment of a third back reef site was prevented by Hurricane Irene in 1999. All sites were located at similar depths $(7$ to $10 \mathrm{~m})$. All coral heads and most other structural features that can serve as centers of territory for $S$. partitus (e.g. rubble piles, boulders, and large rocks with high rugosity; all considered as HRAs) at each site were mapped using a permanent perimeter and 6 transect lines for reference. The spatial accuracy of this technique is approximately $1 \mathrm{~m}$ (Figueira et al. in press).

Data presented here were obtained from a combination of observational studies and manipulative experiments. Our observational studies looked at relationships between various aspects of habitat quality and patterns of habitat use by Stegastes partitus at several spatial scales in order to see if factors related to visual field could be driving fish distributions. We quantified the type of habitat used by juvenile and adult $S$. partitus at all the sites and tested for the importance of factors such as the amount of branching soft coral, the availability of potential territories (HRAs), and the overall habitat complexity (rugosity) by comparing these between the 2 habitats (fore reef and back reef) and correlating each with $S$. partitus abundance at the site level. We then quantified the visual environment

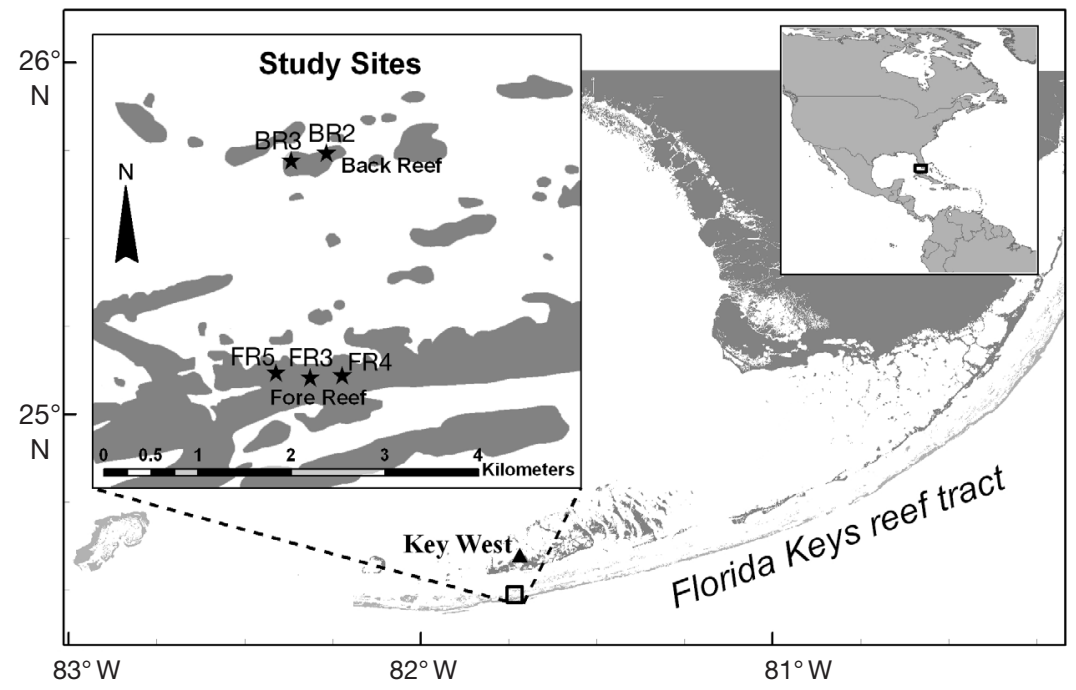

Fig. 1. Study area in the Florida Keys, USA. ( $\star$ ) indicate location of the 3 fore reef and 2 back reef study sites 
at each site and tested for differences between the different habitats. In order to evaluate if it was habitat complexity on the scale of individual territories that was driving fish distributions and not factors related to visual field, we compared measures of habitat type and complexity between areas in open versus limited visual environments. The manipulative experiments build upon the hypotheses generated by the observational studies to actually test the effects of a limited visual field on 2 aspects of fish behavior, movement and courtship. The details of the observational studies and manipulative experiments are presented separately below.

Observational studies. Site-level habitat characteristics and related fish distributions: Previously, we quantified the percent cover of different habitat types $\left(18 \times 0.25 \mathrm{~m}^{2}\right.$ uniform point quadrats per site) and demonstrated that back reef sites had a much higher percent of branching corals than fore reef sites (back reef $=48.5 \% \pm 17.6 \mathrm{SD}$, fore reef $=14.8 \pm 3.9$, Lyman 2002). In order to more closely characterize the amount of soft coral at each site, we used a $1 \mathrm{~m}$ wide PVC ' $\mathrm{H}$ '-frame with $1 \mathrm{~m}$ tall side arms. The frame was placed at $1 \mathrm{~m}$ intervals along each of 2 randomly selected transects at each site. All soft coral branches that fell within $5 \mathrm{~cm}$ of each side of the frame were counted and their height was estimated. We used the number of HRAs (based on site maps) as a proxy for the amount of potential territory centers at the scale of the site. The complexity of the substrate at each site was estimated in a concurrent study (Figueira et al. in press) by measuring rugosity (Luckhurst \& Luckhurst 1978) at $1 \mathrm{~m}$ intervals along all 6 transects at each site.

We compared values between habitats for each of these measures using $t$-tests and also used linear regressions to test for relationships between the mean number of Stegastes partitus per site and: (1) the mean density of coral branches per site; (2) the number of HRAs per site; and (3) the mean rugosity index per site. Regressions were done separately for: (1) adults and (2) recruits and juveniles (combined). Fish abundance estimates were based on means from 5 complete site censuses between 1999 and 2001 (see Figueira et al. in press for details). We noted that recruits and juveniles tended to be found much more often over rubble habitats than massive coral/rock habitats whereas adults displayed the opposite pattern. This might reflect a movement from nearbottom areas with a low visual field to higher areas with a greater visual field. In order to test this relationship we recorded the habitat affiliation of each fish during the last census (10 September 2001). Each recruit/juvenile ( $\leq 50 \mathrm{~mm}$ ) and adult (>50 mm) was scored as to whether it occurred in a coral rubble or a massive coral/rock habitat. Habitat use was compared using Fisher's Exact Test.
Characterizing the visual environment: To determine if there is more open space in the fore than in the back reef and to test if male Stegastes partitus use territories with a visual field which is larger than average for a site, we quantified the visual field at all sites using a photo-quadrat approach. We measured the total open area, the size of the visual field, and the distance to the nearest high-relief objects (mainly gorgonian corals) around 8 random points and 8 points centered in territories (male nests) of large males in each of the back and in 2 of the fore reef sites (FR4, FR5). Random points were selected from the 25 transect line junctions on each site. Fish territory points were those of large males for which we also had information on fecundity (Figueira et al. in press). A PVC pipe cross was placed in the center of the male's territory or at the selected random point. From a height of 3 (fore reef) or $2 \mathrm{~m}$ (back reef, where water visibility was lower), we took 4 photographs, each looking straight down at one corner of the cross, using a digital video camera (Sony TRV-900) in an underwater housing. We combined the 4 pictures using the scaled cross as reference (Adobe Photoshop, version 5.0). Using digital analysis (MOCHA image analysis software, version 1.2) we measured: (1) the percent of open area (area not covered by gorgonian growth) in the picture; (2) the area of visual field-which was designated as the area around the center of the cross that would be visible for a fish located at the center of the cross near the sea bottom (thus not including also the 'shadow' or blind spots created behind objects) - out of the total area included in the picture; (3) the mean distance to all the highrelief objects (e.g. gorgonian corals, large sponges, big coral heads or rocks, normally higher than $1 \mathrm{~m}$ ) closest to the center. We used an ANOVA to test for differences in area (percent area was arcsine square-root transformed) and distance around fish locations versus randomly located points and between back and fore reef habitats with site as a random factor nested in habitat. As with the other site-level variables, we also tested for linear relationships between fish abundance and visual field at each site (only 2 sites for the fore reef). Lastly, we tested for a linear relationship between the size of an open patch in the back reef and the number of fish in it. For that we used the site maps, which indicate the known location of individual fish, and the calculated area of the individual patches in this habitat.

Small-scale habitat quality: Because the aggregation of Stegastes partitus in open patches in the back reef may also be related to higher bottom complexity (rugosity) or higher cover of coral rubble (being an important substrate for fish recruits or adults, Nemeth 1998) in those patches, we tested the difference in these properties between visually open patches and 
the surrounding visually limited environment of the soft coral stands at both back reef sites (only back reef sites were used as fore reef sites do not contain the extensive soft coral fields required for this analysis). For rugosity, we used only $1 \mathrm{~m}$ segments that fell inside areas photographed for visual field estimates, and thus could be identified as an open patch ( $\mathrm{n}=48$ segments) or soft coral field ( $n=27$ segments) areas. A segment was classified as an open patch if there were no high relief soft corals or sponges within a ca. $1 \mathrm{~m}^{2}$ area. To evaluate coral rubble, we used the percent cover quadrat data from Figueira et al. (in press). A quadrat was considered to be located in an open patch if its percent cover of live branching coral was $<40 \%$, and this classification was also verified from our site maps and photographs. Both rugosity and cover were arcsine square-root transformed and compared between visually open and limited areas using a $t$-test.

Manipulative experiments. Effect of visual field limitation on fish behavior: We tested the effect of visual field limitation on the behavior of Stegastes partitus males (50 to $60 \mathrm{~mm}$ total length) by reducing the visual field around them and measuring (1) the time they spent at different distances from the nest and (2) their courtship behavior (number of courtship dips). We manipulated the size of the visual field around males using a visual interference device (VID) that mimicked a circle of branching soft corals at a distance of $0.5 \mathrm{~m}$ from the center of the fish's territory. The VID was made from two $1 \mathrm{~m}$ diameter octagonal PVC-pipe frames, connected one over the other by $60 \mathrm{~cm}$ long pipes. To mimic branches of soft corals we tied eighty $3 \mathrm{~cm}$ wide black nylon strips between the 2 frames, with a gap of $2 \mathrm{~cm}$ between strips (Fig. 2a). Strip density was based on average branch density measured at the back reef site (see 'Results'). The gaps allowed some vision through the VID, and free passage in and out of the device for water, particles (i.e. food) and fish, which was verified in preliminary trials. We used 2 types of controls for this experiment: (1) a VID with transparent strips (Transparent VID, Fig. 2b) and (2) only the base frame octagon, laid on the bottom (No VID, Fig. 2c). The transparent control was added in case it was the physical presence of the vertical strips around the fish rather than the reduced visibility caused by their black color that had some effect on the mobility of the fish through the VID. It also controlled for potential effects on water and food flow as well as on the acoustic environment around the fish (because these fish also use sound to communicate, Myrberg 1972, 1997). However, upon the addition of the experimental VID with black strips within their territories, fish began to move freely through the strips after only a short acclimation time (a few minutes), which provides circumstantial evidence that the fish were not intimidated by the strips themselves. We
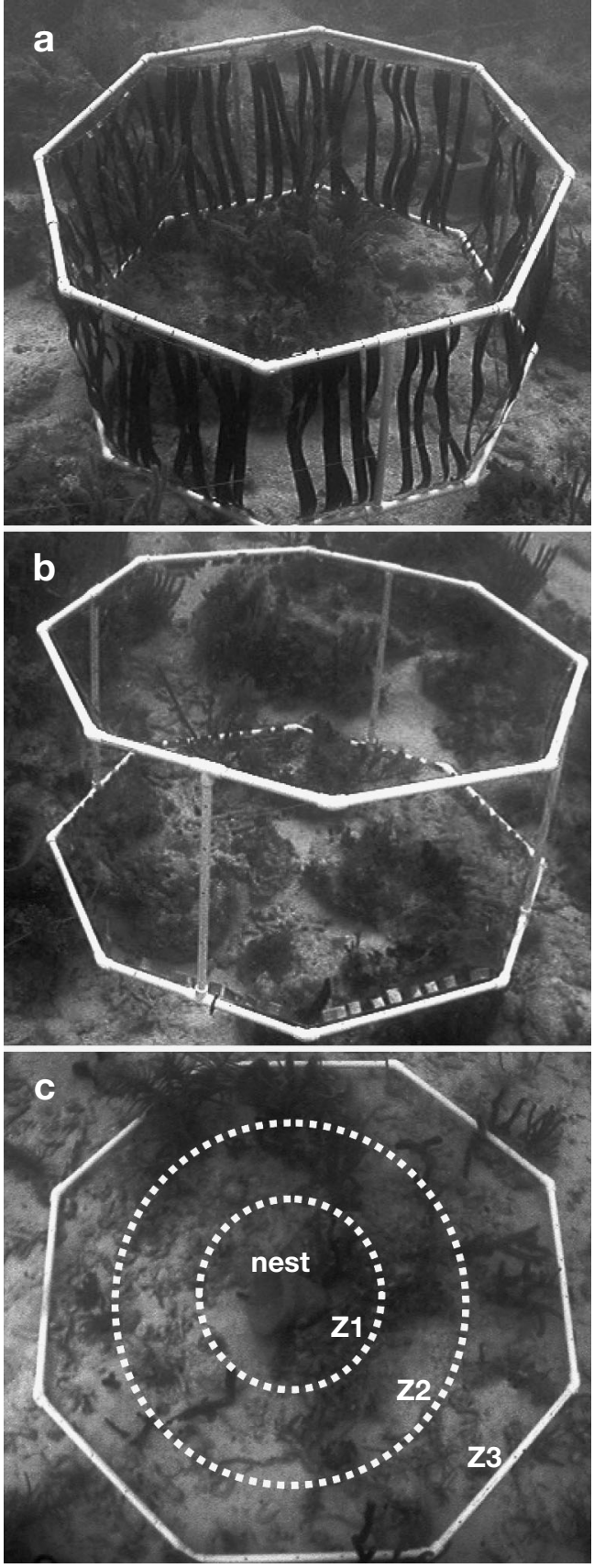

Fig. 2. Stegastes partitus. (a) Black visual interference device (VID) treatment, and controls: (b) Transparent VID and (c) No VID. The nest (the flowerpot in the center) and the different zones (Z1, Z2 and Z3) used for data analysis are illustrated in (c)

used artificial substrate for the VID because manipulating density of live coral would be destructive and because we wanted to standardize the structure as much as possible and to have the treatment and the transparent control structurally similar except for visibility.

We used a three, fixed-factor (visual field treatment, habitat, period) experimental design because we sus- 
pected that there might also be differences in the fish behavior between habitats (back vs. fore reef) and time periods (pre-peak vs. peak spawning periods). We videotaped fish behavior in order to eliminate diver effect and to allow for accurate analysis of fish location in the laboratory. The video camera was mounted on a $2.5 \mathrm{~m}$ high tripod at the southern side of the VID, oriented downwards such that the entire interior of the VID was visible through the lens. We filmed each treatment (Black VID, Transparent VID, and No VID) for $7 \mathrm{~min}$ after a 10 to $15 \mathrm{~min}$ acclimation period (to eliminate the effect of VID placement and diver activity on fish behavior). The order of treatment/controls for each fish was random and videotaping was rotated among 2 to 4 males in a single dive. Altogether, 5 fish were recorded in each of the habitats (fore and back reefs) in the pre-spawning period (20 to 26 August 2001), which was determined from the moon phase (Robertson et al. 1988). Nine and 7 fish were recorded in the fore and back reef, respectively, during the peak spawning period (2 to 4 September 2001). Stegastes partitus spawns at dawn and may reduce its activity at dusk. To avoid possible effect of time of day on fish behavior we conducted all recordings between $08: 30 \mathrm{~h}$ ( $\sim \mathrm{h}$ after dawn) and 16:30 h ( $3 \mathrm{~h}$ before dusk). A diver was floating ca. $3 \mathrm{~m}$ away from the VID during videotaping to record fish activity when the fish left the VID.

We analyzed the videotapes by dividing the VID area into 3 zones $(Z 1, Z 2, Z 3)$ marked around the nest on a clear acetate sheet mounted over the TV screen (see Fig. 2c). Z1 had a radius of $20 \mathrm{~cm}(10 \mathrm{~cm}$ from the nest); Z2: $35 \mathrm{~cm}_{\text {; }}$ and $\mathrm{Z} 3: 50 \mathrm{~cm}$. We recorded the amount of time spent in each zone by watching the video and logging fish movement through zones. If the fish left the VID area, the direction was noted and the time spent away from the VID area was recorded. We calculated the percent of time the fish spent inside the nest, in Z1, Z2 and Z3, and outside the VID area. After an arcsine square-root transformation of percentages to normalize data, we tested the time budget in Z1 among habitats, periods and treatments, using a repeated-measure (RM) ANOVA because we exposed individual males to all 3 treatments one after the other, making treatment a within-effect factor. We did not test the difference in time spent in the other zones because it is dependent on that of $\mathrm{Z1}$, but we show the change in time spent in those zones as a reflection of change in time spent in Z1. The number of courting dips was analyzed using a non-parametric KruskalWallis analysis.

Because of a possible trade-off between a male's reproductive success and its willingness to take risks, we used data collected for a related study to test the effect of a male's success on the extent of its movement in the presence of the VID. The nest used by most males in the experiment was a flowerpot that we provided to allow the measure of each male's reproductive success (see Figueira et al. in press for details of reproductive measurements, and see Fig. 2c). The flowerpot was placed right next to the original male nest. Most males adopt these flowerpots as nests, and females readily lay their eggs in them, which allows for measurement of reproductive success in terms of number and size of egg clutches laid inside the flowerpot (Knapp \& Warner 1991). We used the fecundity data (number of egg clutches in the nest at the day of the experiment, total area of live eggs that day, and total area of clutches laid up until and including that day) to determine relationships between male reproductive success and the time a male spent in the nest or in Z1 in the presence or absence of a VID.

We estimated the distance (to the nearest $0.5 \mathrm{~m}$ ) from the nest of the tested males to large males (competitors) and females (mates) within a radius of $3 \mathrm{~m}$ during the peak spawning VID experiments. This information can help to determine what is the minimum necessary size of a visual field around a mature Stegastes partitus male that would not limit minimal intra-specific interactions. Males rarely travel more than $3 \mathrm{~m}$ away from their shelter (G. Rilov, S. J. Lyman \& W. F. Figueira pers. obs.). Sex of neighbors was determined from the type of interactions the focal males exhibited towards the fish around it (i.e. aggression or courtship). Potential difference between the distance to males and females was analyzed using non-parametric KruskalWallis analysis.

Visual field limitation and male courtship behavior in the presence of a predator: Because courting rates were highly variable among males in the first experiment, the effects of visual limitation on courting were suggestive but inconclusive (see 'Results'). Also, we could not differentiate if the VID effects on courtship behavior were related to increased predation risk or to reduced visibility of nearby females. Therefore, we tested more explicitly the effect of visual field limitation on male courtship in the presence of a clearly visible female within the VID area. In order to keep potential predation risk constant we also exposed the male to an actual predator, which was present (but contained) outside the VID area. We placed, in a random order, black and transparent VIDs around the male Stegastes partitus and exposed the fish to a predator (graysby grouper Cephalopholis cruentatus) and to a female. We did not use the 'No VID' treatment because of the lack of a difference between it and the transparent control in the previous experiments (see 'Results').

The experiment was conducted during 3 dives on 28 August 2001 between 09:00 $\mathrm{h}$ and 16:00 $\mathrm{h}$ at a fore reef 
site (FR5), and we used videotaping to record fish behavior using the same setup as described above. First, a VID (Black or Transparent) was placed around the male. Next, a grouper in a $30 \mathrm{~cm}$ diameter clear plastic ball was placed right outside the VID. After a $15 \mathrm{~min}$ acclimation time we recorded fish behavior inside the VID for 2 min without a female, as background reference behavior. Then, a female in a $15 \mathrm{~cm}$ diameter clear plastic ball was placed $15 \mathrm{~cm}$ away from the male's nest using a long PVC pole so the diver was never closer than approximately $2 \mathrm{~m}$ to the male. The male behavior was recorded again for a further $2 \mathrm{~min}$. Each male ( $\mathrm{n}=9$ males) was exposed to both the Black (treatment) and Transparent (control) VID, and the order of presentation of treatment and control was assigned randomly. From the videotapes, we calculated the time the male spent in the area of the female's ball (i.e. first in the area where the ball with the female would be located, and then within $\sim 5 \mathrm{~cm}$ from the ball when the ball was placed in the VID area), the number of 'attention' events and the number of courting dips. Attention events included behavior such as female inspection, fin flutter, color change, and body flick (none of these behaviors were observed in preliminary trials introducing the ball to the male with no female inside it). We used the difference in the magnitude of these behaviors between + and - female conditions as the measure to be compared between the Black and Transparent VID treatments. A $t$-test was used to test the null hypothesis of no difference in percent time spent in the ball area, attention events and courtship dips between the Transparent and Black VID.

\section{RESULTS}

\section{Observational study}

\section{Site-level habitat characteristics and related fish} distributions

Both soft coral density $(22.5 \pm 1.7 \mathrm{SE}$ and $4.7 \pm 0.7$ branches $\mathrm{m}^{-1}$ in the back reef and fore reef, respectively, $t$-test $\left.t_{1,68}=10, \mathrm{p}<0.0001\right)$ and height $(46.5 \pm 2.5$ and $28.3 \pm 1.7 \mathrm{~cm}$, respectively, $t$-test $t_{1,108}=5.6, \mathrm{p}<$ $0.0001)$ were significantly greater on the back reef than on the fore reef. A strong negative relationship was found between mean soft coral density and mean number of recruits/juveniles and of adults per site (Fig. 3a, $F_{1,4}=41.4, p=0.007$; Fig. 3b, $F_{1,4}=9.9, p<$ 0.05 , respectively). The number of HRAs per site was similar in the back and fore reef $(129 \pm 12 \mathrm{SE}$ and $139 \pm 30$, respectively). Overall, the back reef sites were significantly more rugose than the fore reef sites $(1.51 \pm 0.08 \mathrm{SE}, \mathrm{n}=18$ and $1.30 \pm 0.08, \mathrm{n}=12$; Mann-
Whitney $U$-test $\mathrm{p}_{2 \text {-tail }}<0.001$, Figueira et al. in press). No significant relationship was found between number of HRAs per site or the rugosity index and number of fish (Fig. 3c-f). On both the fore and back reef, recruits/juveniles tended to be found disproportionately over rubble and adults over massive coral/rock (Fisher's Exact Test; fore reef, $\mathrm{p}=0.0461$; back reef, $\mathrm{p} \ll 0.0001)$.

\section{Visual environment}

Total open area, relative size of visual field and distance to nearest objects were all greater in the fore reef than in the back reef, both around fish territories and random points (Table 1, Fig. 4). Open area and visual field were also greater around fish points than would be expected at random (Table 1, Fig. 4). There was a weak interaction between habitat and point in total open area because the difference between fish and random point was smaller in the fore reef compared to the back reef. The difference in the size of the visual field between the back and fore reef was greater around random points (fore reef - back reef $=22 \%$ ) than around fish points (17\%), suggesting that the fish are found in more open areas regardless of the habitat. The mean size of the visual field around random points positively correlated with both the number of recruits

Table 1. Effect of Habitat (back and fore reef), Site (nested within Habitat) and Point where the photos were taken (Random or Fish) on the relative size of the open area, the relative size of the visual field, and the mean distance to the nearest high-relief object. Significant p-values $(\alpha=0.05)$ in bold

\begin{tabular}{|lrrrrc|}
\hline Source of variation & df & \multicolumn{1}{c}{ SS } & MS & $F$ & $\mathrm{p}$ \\
\hline Open area & & & & & \\
Habitat & 1 & 27.4 & 27.4 & 185.2 & $\mathbf{0 . 0 0 5}$ \\
Site(Habitat) & 2 & 0.3 & 0.1 & 0.7 & 0.601 \\
Point & 1 & 13.9 & 13.9 & 62.4 & $\mathbf{0 . 0 1 6}$ \\
Site(Habitat) $\times$ Point & 2 & 0.4 & 0.2 & 0.4 & 0.654 \\
Habitat $\times$ Point & 1 & 4.4 & 4.4 & 19.8 & $\mathbf{0 . 0 4 7}$ \\
Error & 58 & 30.2 & 0.5 & & \\
Visual field & & & & & \\
Habitat & 1 & 30.0 & 30.0 & 26.5 & $\mathbf{0 . 0 3 6}$ \\
Site(Habitat) & 2 & 2.3 & 1.1 & 0.7 & 0.579 \\
Point & 1 & 38.4 & 38.4 & 24.7 & $\mathbf{0 . 0 3 8}$ \\
Site(Habitat) $\times$ Point & 2 & 3.1 & 1.6 & 2.0 & 0.142 \\
Habitat $\times$ Point & 1 & 4.5 & 4.5 & 2.9 & 0.232 \\
Error & 58 & 44.9 & 0.8 & & \\
Distance & & & & & \\
Habitat & 1 & 107114.2 & 107114.2 & 54.9 & $\mathbf{0 . 0 1 8}$ \\
Site(Habitat) & 2 & 3902.8 & 1951.4 & 1.4 & 0.421 \\
Point & 1 & 19388.0 & 19388.0 & 13.7 & 0.066 \\
Site(Habitat) $\times$ Point & 2 & 2835.8 & 1417.9 & 1.3 & 0.268 \\
Habitat $\times$ Point & 1 & 265.3 & 265.3 & 0.2 & 0.707 \\
Error & 58 & 61079.2 & 1053.1 & & \\
\hline & & & & & \\
\hline
\end{tabular}



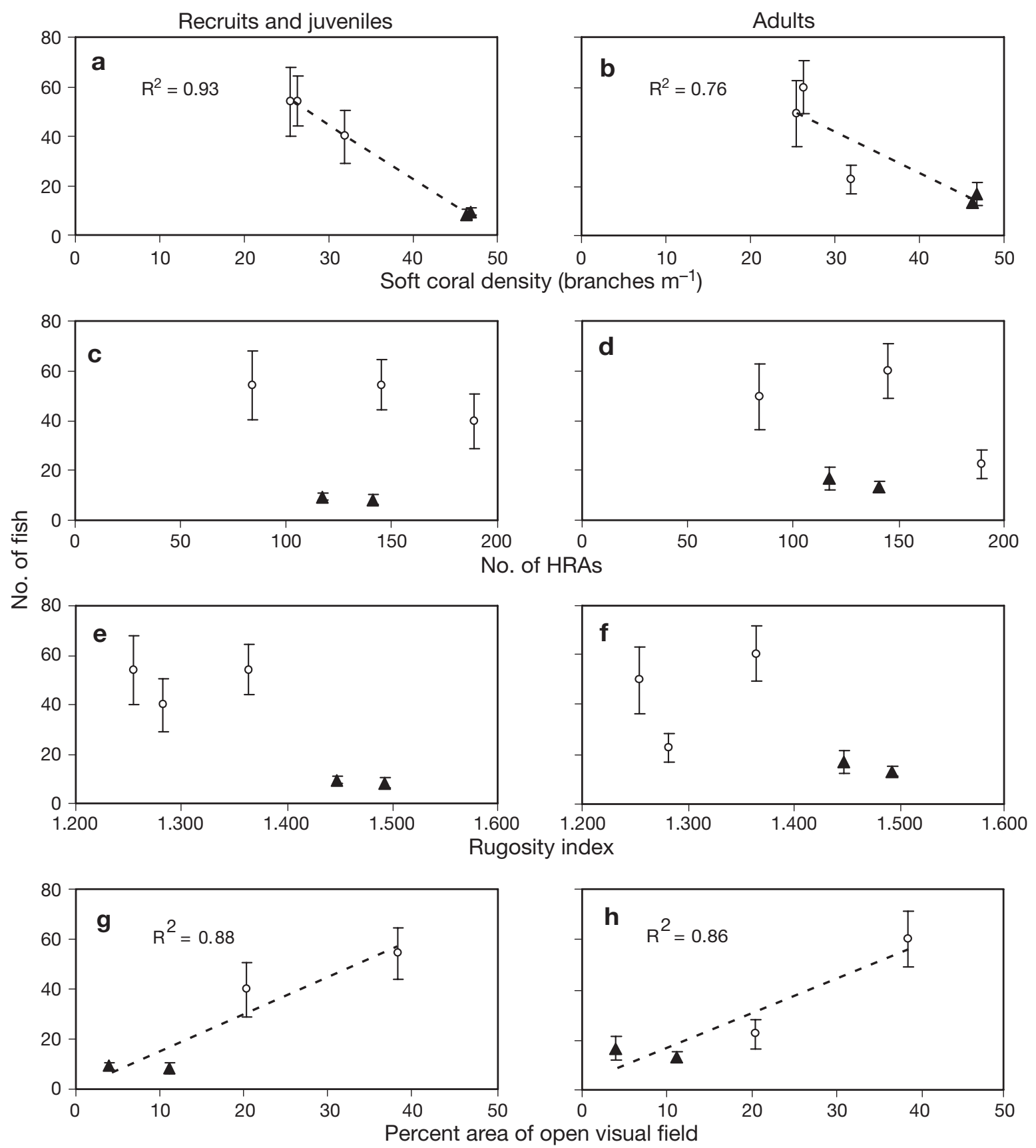

Fig. 3. Stegastes partitus. Regression between mean $( \pm 95 \%$ SE) number of: $(a, c, e, g)$ recruit/juvenile fish and $(b, d, f, h)$ adults per site (average values from 5 censuses during the study period), and density of soft corals, number of high rugosity areas (HRAs), rugosity index and the percent of open visual field around random points (only 2 fore reef sites for this factor). $\mathrm{O}=\mathrm{Fore}$ reef sites; $\boldsymbol{\Delta}$ = Back reef sites. Significant best fit lines $(\mathrm{p} \leq 0.05)$ are shown were applicable (dashed line)

plus juvenile fish and with the number of adults (Fig. $3 g$,h). In the back reef, only 5.9 and $12.9 \%$ of the total number of fish in BR2 and BR3, respectively, were not found in open patches. There was also a strong positive relationship between the size of an open patch and the number of fish in the back reef sites $\left(\mathrm{r}^{2}=0.89\right.$, $\left.F_{1,4}=136.6, \mathrm{p}<0.001\right)$.

\section{Small-scale habitat quality}

The mean rugosity index was between 1.4 and 1.5 and did not differ between visually open and visually limited areas in the back reef $\left(t\right.$-test, $\left.t_{65}=0.98, \mathrm{p}=0.32\right)$. Percent rubble cover was $\sim 3 \%$ and also did not differ between open and limited areas ( $t$-test, $t_{33}=-1.3, \mathrm{p}=0.18$ ). 
Fig. 4. Stegastes partitus Mean $( \pm 95 \%$ confidence limits) of (a) percent open area , (b) visual field (\% of total area), and (c) distance to closest high-relief objects around random and fish points in the back reef (BR) and fore reef (FR) habitats. All means were significantly different from each other at a $p<0.0001$ level. Lines connecting points are shown to better illustrate the difference between random and fish points

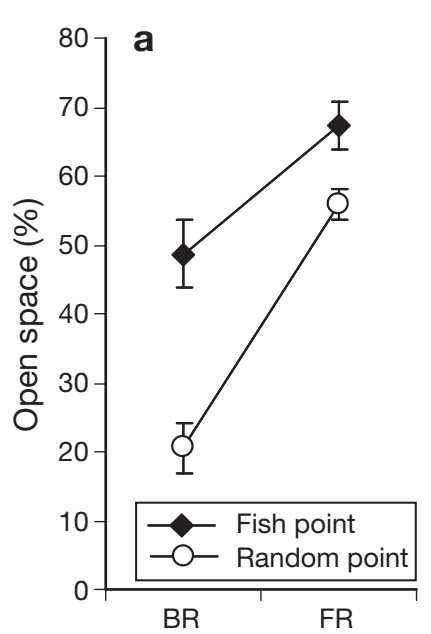

\section{Manipulative experiments}

\section{Effect of visual field limitation on fish behavior}

The ANOVA revealed significant effects of habitat and treatment on male behavior and an interesting interaction between habitat and period (Table 2). Generally, males in the fore reef spent more time in the nest than back reef males and increased the time spent in the nest at the peak spawning period (Fig. 5a). Time spent close to the nest $(<20 \mathrm{~cm}$ from the center of territory) increased by 30 to $100 \%$ when the visual field was limited (Black VID) compared to both controls (treatment effect, p $<0.0001$ ), and the effect was stronger in the back reef (treatment $\times$ habitat interaction, $\mathrm{p}=0.012$, Fig. 5b, Table 2). There was also a strong habitat $\times$ period interaction effect on the time spent $<20 \mathrm{~cm}$ whether the VID was there or not (Table 2) because males in the fore reef stayed closer to
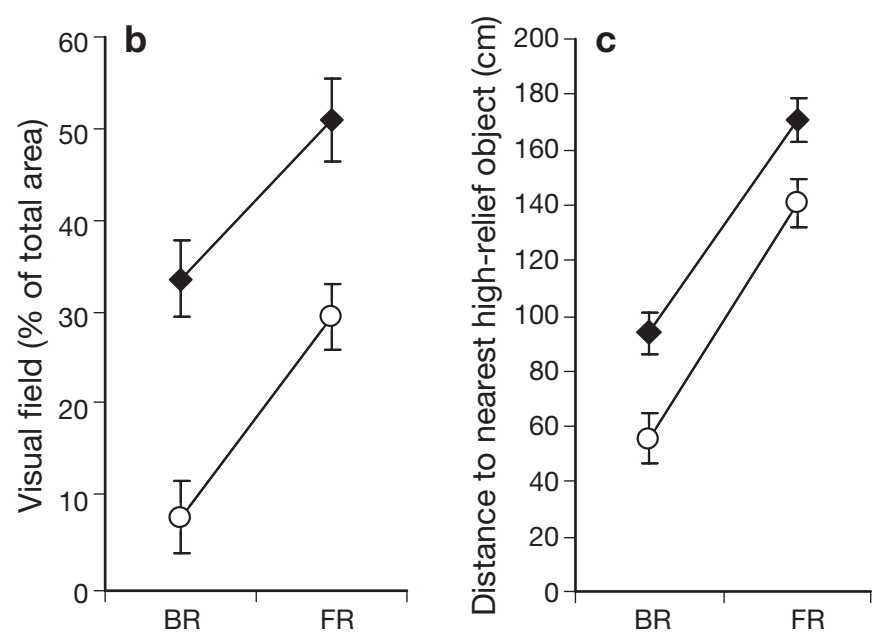

the nest during peak spawning than during the prepeak period, whereas males in the back reef moved further away at the peak of spawning (Fig. 5b,e). Notably, the fish spent between 70 and $100 \%$ of the time within $50 \mathrm{~cm}$ from the center of the territory (combining the time spent in Z1, Z2 and Z3, i.e. the entire VID area), even when no VID was present. Time spent further than $50 \mathrm{~cm}$ decreased in the fore reef between the pre-peak spawning and the peak spawning periods, and was generally very low in the back reef (between 0 and 10\%, Fig. 5e). Limiting the visual field (Black VID) reduced the time spent outside the VID area compared to controls, most noticeably so during the pre-peak period in the fore reef. The number of courting dips appeared to be lower in the Black VID treatment compared to the Transparent and No VID controls $(1.46 \pm 0.90 \mathrm{SE}, 2.58 \pm 0.95$ and $2.84 \pm 0.92$, respectively, Kruskal-Wallis non-parametric analysis, $\mathrm{p}=0.07$ ); however, post-hoc tests showed no significant differences among any of the treatments because of high levels of variance in the number of dips among males within treatment. The mean estimated distance of large males and females to the tested males ranged between 1.3 and $2.3 \mathrm{~m}$, and differed between sexes only in the back reef site, males being more distant than females $(2.4 \pm$ $0.27 \mathrm{SE}$ and $1.3 \pm 0.22 \mathrm{~m}$, respectively; nonparametric Kruskal-Wallis analysis, $H_{1,18}=$ 6.03, $\mathrm{p}=0.014)$.

The fish behavior did not differ between the 2 control treatments (No VID and Transparent VID) in most cases (LSD post hoc test: p $>0.14$ in 3 out of 4 cases and a marginal difference in the back reef in the pre-peak spawning period, $\mathrm{p}=0.044)$. The reduced movement within Black VID treatments did result in fewer forays out of the Black VID 

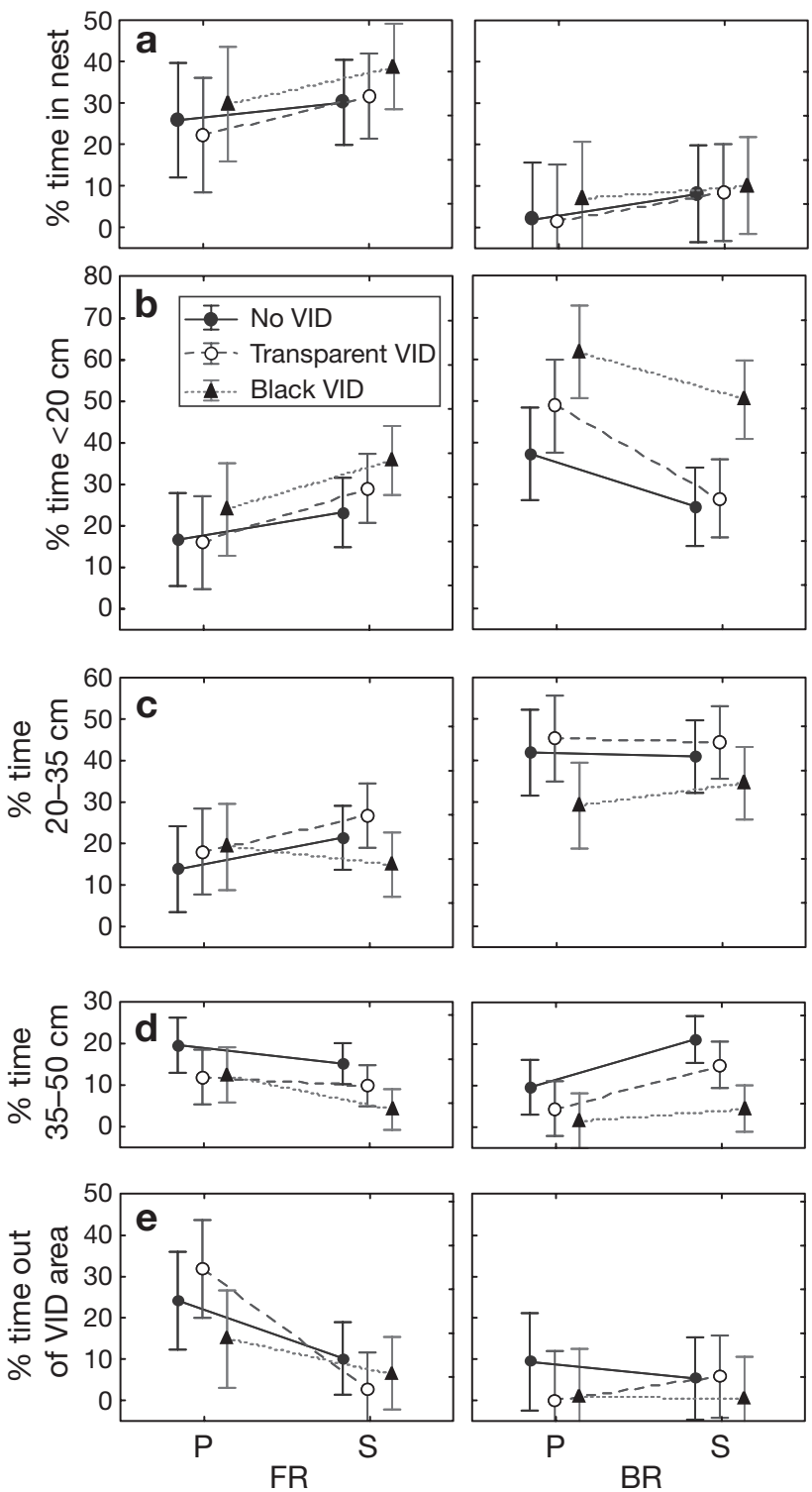

Fig. 5. Stegastes partitus. Mean ( $\pm 95 \%$ confidence limits) of time spent by males (a) inside the nest, (b) within $20 \mathrm{~cm}$ from the center of territory, (c) between 20 and $35 \mathrm{~cm}$ from the center of territory, (d) between 35 and $50 \mathrm{~cm}$ from the center of territory, and (e) outside the VID area, in Black VID, Transparent VID and No VID treatments in the back reef (BR) and fore reef (FR) habitats and in the pre-peak (P) and peak spawning (S) periods

(number of times a fish crossed the VID border per observation period) compared to the transparent one $(1.4 \pm 4.25 \mathrm{SD}$ and $2.9 \pm 15.2$, respectively); however, the difference was not significant $(\mathrm{p}=0.06,2$-tail $t$-test). These facts suggest that fish were not merely 'intimidated' by the Black VID itself. Rather, the fact that they could not clearly see what goes on beyond the VID restricted their movement, probably because of a higher degree of uncertainty about the risk of predation.
The area of live egg clutches in the nests of male test fish was higher in the fore reef than the back reef $\left(70.8 \pm 12 \mathrm{SE}\right.$ and $19.1 \pm 11.9 \mathrm{~cm}^{2}$, respectively). There was a significant positive relationship between the total area of live egg clutches found in the nest around the peak spawning period and the time a male spent in the nest both with Black VID present and with No VID $\left(\mathrm{r}^{2}=0.38, \mathrm{p}=0.02\right.$ and $\mathrm{r}^{2}=0.34, \mathrm{p}=0.02$, respectively, Fig. $6 \mathrm{a}, \mathrm{b})$. There was a nearly significant correlation with time spent within $20 \mathrm{~cm}$ from the center of the territory when Black VID was present around the males, but not with No VID $\left(r^{2}=0.17, p=0.07\right.$ and $r^{2}=$ $0.05, p=0.20$, respectively, Fig. $6 c, d)$. Similar results were found for total area of clutches laid until the day of the experiment (not shown), but the number of clutches did not significantly correlate with movement. Males with more eggs in their nest responded more strongly to visual field limitation than males with fewer eggs by spending more time in the nest (Fig. 6e).

Visual field limitation and male courtship behavior in the presence of a predator

Males spent more time in the female ball area and displayed more 'attention' behaviors when the ball with the female was present than when absent (this demonstrates that the males were responding to the presence of the female). There was no difference in time spent near the ball with a female and in the number of attention events between the Black VID and Transparent VID treatments (Fig. 7a,b). The male displayed more courtship dips when the VID around it was transparent than when it was black (Fig. 7c).

\section{DISCUSSION}

Our study offers a new perspective on potential mechanisms that can affect the distribution of siteattached, territorial prey species. First, we have shown that the distribution of fish may be related to the size of the visual field (open area) around them. Next, we showed that limiting the visual field affects important components of behavior, i.e. movement and courtship rates. We also found evidence for a potential interaction between reproductive success and the effect of visual field limitation. Still lacking, however, is a direct causative link between the short-term effects of a limited visual field as demonstrated in this study and the distribution of the fish. Two findings - (1) the negative relationship between the abundance of Stegastes partitus per site and habitat complexity on the scale that affects the visual field (i.e. soft coral density), and (2) the positive relationship of fish abundance with the 


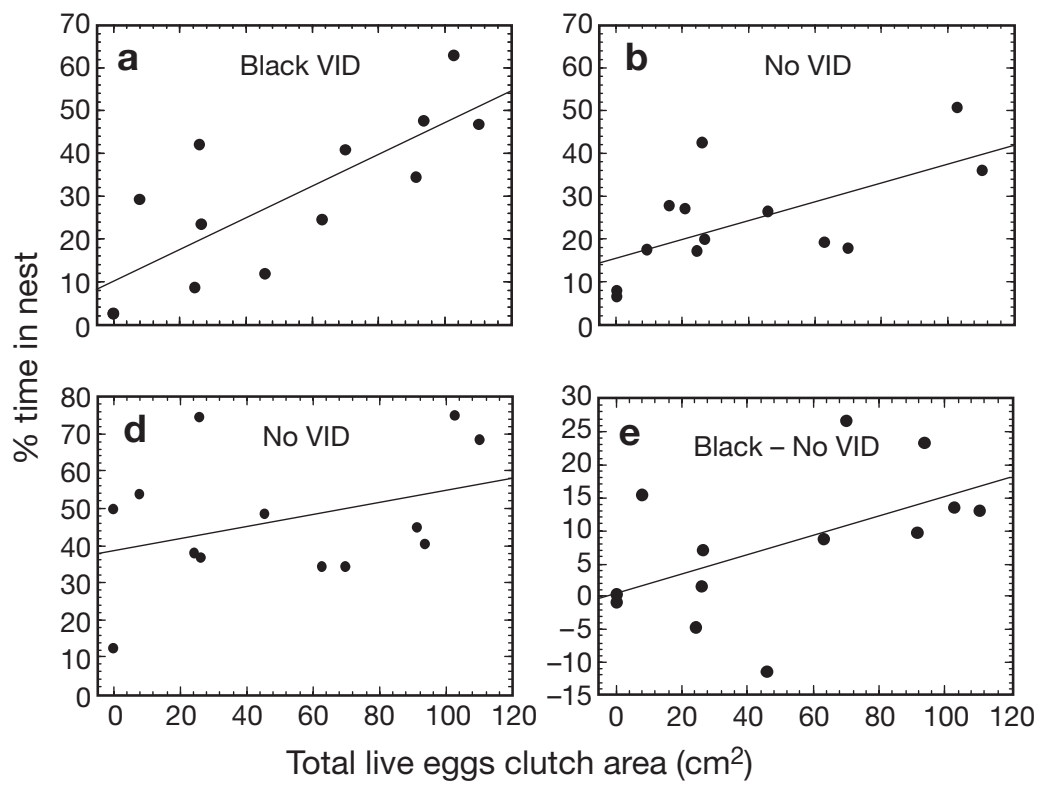

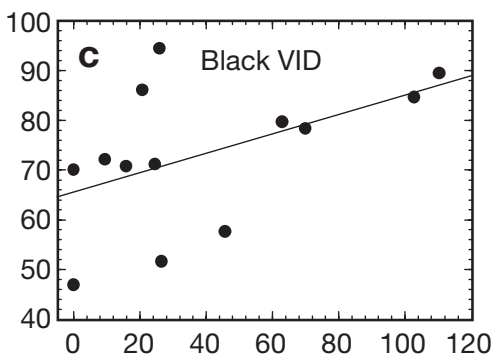

Total live eggs clutch area $\left(\mathrm{cm}^{2}\right)$

Fig. 6. Stegastes partitus. Regression between the total live eggs clutch area in the nest of the males tested in the VID experiment at the day of the experiment, and the time spent in the nest or within $20 \mathrm{~cm}$ distance from the center of territory $(\mathrm{a}, \mathrm{c})$ when surrounded by Black VID, (b,d) No VID control, and (e) the difference between the Black and No VIDs. Data from all sites are shown size of open visual field within a site-do however support the notion that fish abundance is related, at least partially, to the quality of the visual field. We believe that our work is the first step needed to establish the visual field-behavior-abundance connection. We discuss our results within a conceptual framework that shows the links we have established and suggest the assumed links that stem from them (long-term effects that can influence fitness), which require testing in future studies.

\section{Size of visual field and fish behavior}

Measuring directly the visual field around random points in the back and fore reef demonstrated that the visual field is much smaller in the back reef. We
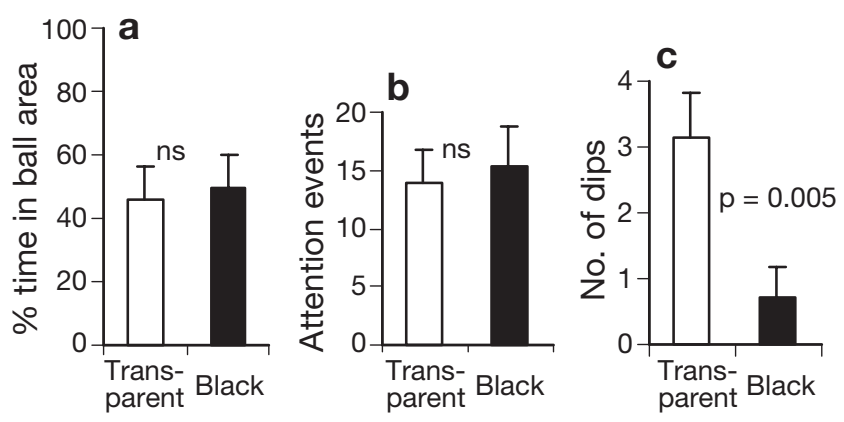

Fig. 7. Stegastes partitus. Effect of a Transparent or a Black VID on (a) the percent time spent by a male in the area where the transparent ball with a female was placed, (b) the number of attention behavior events and (c) the number of courtship dips performed by a male in the presence of a predator outside the VID area. The test statistic was the difference between observations with and without a female present inside the VID area. ns = non significant showed that Stegastes partitus occupies territories with a larger than average visual field, in both the back and fore reef. Our experiments demonstrated that artificially reducing the visual field around males constrains their movement, forcing them to spend more time closer to the nest. Visual field limitation had a stronger effect on back reef males, perhaps because they already live in a more confined environment and thus are conditioned to a high degree of uncertainty about predation risk. Limiting the visual field also reduced male courtship behavior (dips). Fish may decrease courtship displays when the visual field is limited because dips involve rapid and very conspicuous movements plus auditory signals that might attract predators lurking close by, concealed behind the visual barrier. This, of course, can increase risk of predation. Alternatively, a limited visual field can reduce visual contact with mates, and thus restrict courtship behavior. Our predator-exposure experiment supports the first hypothesis because females were presented inside the VID, thus close and clearly visible to the male. In the presence of a predator immediately outside the Transparent or Black VID, male $S$. partitus approached the presented female and demonstrated subtle 'attention' behaviors, but with the Black VID it dramatically reduced its dipping rates. We suggest that uncertainty about risk of predation (unknown risk) limits courtship behavior, while in the presence of a known risk (a clearly visible predator) a male is better able to 'decide' if the reward of courting is worth the risk.

Male Stegastes partitus court either inside their own territories as females venture nearby, or near female territories during foray bouts to display their courtship dips (G. Rilov pers. obs.). The mean distance of tested males to large females (within a range of $3 \mathrm{~m}$ ) in our 
study sites ranged between 1.2 and $2.5 \mathrm{~m}$, indicating that most males need to travel this distance from their shelter in order to visit females. Interestingly, although males sometimes traveled up to $3 \mathrm{~m}$ away from their nest to visit females (data not presented), more than $70 \%$ of the time they remained within $50 \mathrm{~cm}$ from the center of their territory, even when no VID was present (No VID control). This suggests that the ecological neighborhood - the area in which an organism spends most of its time (sensu Addicott et al. 1987) — of male $S$. partitus is constrained to an area the size of $\sim 0.8 \mathrm{~m}^{2}$ or less, a territory size similar to that of $S$. planifrons, a congener herbivore with similar body size (Meadows 2001). This size territory means that local predators should be able to reliably predict the location of the male most of the time. Limiting the visual field increased the time males spent closer to the territory center $\left(<20 \mathrm{~cm}\right.$, i.e. within an area of only $\left.0.13 \mathrm{~m}^{2}\right)$, thus reducing the fish ecological neighborhood even further. This response also seems to be context dependent: males with more eggs responded more strongly to visual field limitation, suggesting that when more eggs are present males are more wary of the uncertainty of predation risk to themselves and/or to their eggs.

The contrasting spatio-temporal behavior between back and fore reef males - back reef males moving further away from the nest; fore reef males moving closer and spending more time in the nest during the spawning peak - may be a product of habitat-dependent male reproductive success. Males in the back reef began receiving eggs much later in the reproductive cycle (near the lunar peak) than fore reef males (Lyman 2002). It is possible that at the peak of the spawning cycle, 'desperate' males in the back reef that do not have many eggs to guard are more risk-tolerant than fore reef males with their higher reproductive success. We found a strong correlation between the area of egg clutches received by a male and the time the male spent in its nest, with or without the VID. This is probably because more eggs means more maintenance and guarding activity (see also Lyman 2002). It also explains why fore reef males spent more time in the nest than back reef males in both the pre-peak and peak spawning periods.

\section{Habitat complexity and fish distribution and abundance}

The aggregation of Stegastes partitus in open patches in the back reef and the strong correlation of size of the patch with fish numbers suggest that the soft coral fields that surround those patches represent a low quality habitat for S. partitus. Appropriate sub- strate at the territory/shelter scale is not the limiting factor in the soft coral fields, because rugosity and rubble percent cover were similar inside both soft coral fields and open patches in the back reef sites. Since $S$. partitus adults normally feed on plankton above the height of most gorgonians (G. Rilov pers. obs.), differences in food availability are unlikely to be the major reason for this aggregated fish distribution. The evidence described above strongly suggests that the more restricted visual field within the soft coral fields is at least partially responsible for the clumped distribution of $S$. partirus in the open patches of the back reef habitat.

Syms \& Jones (2001) experimentally manipulated the density of soft corals on patch reefs and showed no effect on fish density. The differences between our study and theirs are the size of patches and the type of soft corals covering the rocks. Their study was conducted only on small patch reefs, and the dominant forms of soft corals on them were massive (e.g. Lobophytum and Sinularia). We conducted the study on both small patches (fore reef), and on large patches (back reef), and the dominant soft coral species in our study area were gorgonians that are usually much higher in relief and thus can form a high visual barrier. We suggest that on small patch reefs surrounded by sand, soft corals do not create a serious visual problem for territorial fish because the corals are found on the patch while the fish usually swim around it (G. Rilov pers. obs.) and thus the fish should relatively easily identify approaching predators and more easily assess predation risk. This should also allow for greater mobility to other nearby patches (to court or relocate) when the risk is low. However, on the large rocky slabs of the back reef, the almost continuous cover of soft corals can limit the detection of predators, competitors, and mates. In such seascapes, Stegastes partitus are restricted to areas that supply a large enough visual field (open patches within the soft coral fields), and they form relatively isolated aggregations with more limited movement between them. Indeed, there is evidence for greater mobility of individuals in the fore reef (Figueira 2002). We also showed that recruits and juveniles of $S$. partitus inhabit mainly rubble piles, and they switch to living on massive coral or rocks as they grow. It is more than likely that they move to higher relief habitats not only to have greater access to plankton when switching from benthic feeding to planktivory (Nemeth 1998), but also to increase their visual field, as rocks and coral heads probably offer a better view of their surroundings. We argue that in order to observe mates and assure effective courtship display, and at the same time to be confident that it can retreat safely to its shelter, the fish requires a territory with a suitably large visual field. Figueira et al. (in press) have suggested that differ- 
ences in demographic rates of fish in the back and fore reef habitats are due in part to an increased predation risk on the fore reef habitat relative to the back reef habitat. This is not due to differences in the number of predators, but rather to the suitability of the habitat as a refuge from predation. Key factors were the substrate complexity and availability of hidey-holes. The present study demonstrates the additional importance of the visual environment, which can serve to modify not necessarily the predation pressure directly, but rather the uncertainty about that predation pressure. Habitat use patterns indicate a balance between the protection and the risk afforded by habitat complexity. As a result, on the visually limited back reef, fish tend to occupy the habitat with the best small-scale complexity that still allows for a large visual field.

Although we cannot at this point demonstrate that availability of visually favorable habitat is directly related to fish abundance, our correlative results suggest that the density and spatial arrangement of gorgonians affect the overall abundance of Stegastes partitus in the habitat. Soft coral height and density were much higher on the back than on the fore reef. The negative correlation between soft coral density and fish abundance, and the lack of correlation with the number of HRAs (potential fish territories) or the rugosity index (complexity at the territory scale), all suggest that, among the measured habitat features, site-scale complexity is most strongly related to fish abundance. We propose that a more open visual environment allowed greater use of potential territories (HRAs) by $S$. partitus in the fore reef. This, together with higher recruitment rates in the fore reef (Figueira 2002), may be responsible for the greater overall density of $S$. partitus in the fore reef compared to the back reef although survival rates per se were lower in the fore reef (Figueira et al. in press).

Other environmental factors such as plankonic food supply could potentially contribute to differences in fish abundance between habitats. Dissolution block studies showed that water flux was greater on the fore reef; however, tube trap sampling of plankton indicated that food supply was similar between the 2 habitats (Figueira 2002), thus making food supply an unlikely major factor affecting the difference in Stegastes partitus abundance between the 2 habitats.

\section{CONCLUSIONS AND A CONCEPTUAL FRAMEWORK FOR FUTURE RESEARCH}

This study presents some intriguing insights into the relationship between visual field, behavior, and the distribution of territorial site-attached prey species. We have demonstrated primary effects on fish behavior, but it is clear that prolonged exposure to reduced visual field can have secondary effects on fish fitness. These effects can be direct, by reducing fish survivorship due to higher predation, or indirect, due to reduced growth (less feeding opportunities when confined closer to shelter) that ultimately result in a greater susceptibility to predation (Booth \& Hixon 1999) or may reduce reproductive success (Knapp 1995). The trade-off here is clear-court, feed, and risk predation, or stay home and survive. However, staying near home with a limited visual field is costly in the long run because it can affect fecundity indirectly by reducing courtship interactions and thus reproduction. Ultimately, reduced reproduction leads to reduced fitness. We suggest that the demonstrated primary and assumed secondary negative effects on the fish fitness are key factors driving behavioral modifications and ensuing habitat selection of Stegastes partitus. As a consequence, the fish avoids using areas where soft coral cover is high and continuous, resulting in different distribution and abundance of its population in different habitats (e.g. back and fore reef sites in the Florida Keys).

Alternatively, it may not be primarily selection that produces the aggregated distribution in the back reef but rather differential mortality, i.e. Stegastes partitus settles equally within dense gorgonian fields and in open patches but its mortality is higher in the former. Our censuses and observations however suggest that settlers are very scarce within gorgonian fields. It is also known that Stegastes spp. recruits do select their habitat (Guiterrez 1998). Releasing naïve juveniles and adults in a back reef habitat cleared from conspecifics and following where they settle and their survivorship would help to tease apart the effects of behavioral habitat selection versus differential mortality. To test the secondary effects of a limited visual field on fish fitness, controlled experiments are needed in which a fish is exposed to predation while the visual field is manipulated and survivorship, growth and reproductive output are measured. We expect that in a limited visual field environment, direct mortality by predation is most important at the settlement to juvenile stage (Carr \& Hixon 1995) and reduced reproduction is more important in the adult stage. Long-term manipulations of the size of the visual field will also reveal if an individual fish will reduce reproduction over time, or try to change the location of its territory when the visual field is limited. This represents another trade-off because moving among territories can expose a fish to predation as well. Finally, we suggest that the links between visual field, behavior, and distribution be tested in other site-attached territorial prey fish (e.g. gobies and blennies), and other marine and terrestrial taxa, as these links may play a role in the mechanisms shaping community structure. 
Acknowledgements. Many thanks to J. Cohen and G. Piniak for assistance in the field, and to J. Priddy for help with computing. We thank B. Kennington and A. Anderson of SubTropic Dive Center for technical support in Key West. The research was funded by Environmental Defense, Oak Foundation, PADI Foundation, a Fulbright post-doctoral fellowship (G.R.), and graduate fellowships from Duke Marine Lab Fellowship and McCurdy Endowment Fund (S.J.L. \& W.F.F.). The research was conducted under FKNMS permit numbers FKNMS-99-057 and FKNMS2001-002

\section{LITERATURE CITED}

Addicott JF, Aho JM, Antolin MF, Padilla DK, Richarson JS, Soluk DA (1987) Ecological neighborhoods: scaling environmental patterns. Oikos 49:340-346

Anderson TW (2001) Predator responses, prey refuges, and density-dependent mortality of marine fish. Ecology 21:245-257

Bay LK, Jones GP, McCormick MI (2001) Habitat selection and aggression as determinants of spatial segregation among damselfish on a coral reef. Coral Reefs 20:289-298

Booth DJ, Hixon MA (1999) Food ration and condition affect early survival of the coral reef damselfish, Stegastes partitus. Oecologia 121:364-368

Brown GE (2003). Learning about danger: chemical alarm cues and local risk assessment in prey fishes. Fish Fish 4:227-234

Candolin L, Voigt HR (2001) Correlation between male size and territory quality: consequence of male competition or predation susceptibility? Oikos 95:225-230

Carr MH, Hixon MA (1995) Predation effects on early postsettlement survivorship of coral-reef fishes. Mar Ecol Prog Ser 124:31-42

Carr MH, Anderson TW, Hixon MA (2002) Biodiversity, population regulation, and the stability of coral-reef fish communities. Proc Natl Acad Sci 99:11241-11245

Crowder LB, Cooper WE (1982) Habitat structural complexity and the interaction between bluegills and their prey. Ecology 63:1802-1813

Figueira WF (2002) Metapopulation dynamics of coral reef fish: understanding habitat, demography, and connectivity in source-sink systems. PhD dissertation, Duke University, Durham, NC

Figueira WF, Lyman SJ, Crowder LB, Rilov G (in press) Smallscale demographic variability of the bicolor damselfish Stegastes partitus, in the Florida Keys, USA. Environ Biol Fishes

Fuelling O, Halle S (2004) Breeding suppression in free-ranging grey-sided voles under the influence of predator odour. Oecologia 138:151-159

Greenberg LA, Paszkowski CA, Tonn WM (1995) Effects of prey species composition and habitat structure on foraging by two functionally distinct piscivores. Oikos 74:522-532

Gronell AM (1989) Visiting behavior by females of the sexually dichromatic damselfish, Chrysiptera cyanea (Teleostei: Pomacentridae): a probable method of assessing male quality. Ethology 81:89-122

Gutierrez L (1998) Habitat selection by recruits establishes local patterns of adult distribution intwo species of damselfishes: Stegastes dorsopunicans and S. planifrons. Oecologia 115: 268-277

Heck KL, Crowder LB (1991) Habitat structure and predatorprey interactions in vegetated aquatic systems. In: Bell SS, McCoy ED, Mushinsky HR (eds) Habitat structure, the physical arrangement of objects in space. Chapman \& Hall, London, p 281-299

Helfman GS, Winkelman DL (1997) Threat sensitivity in bicolor damselfish: effects of sociality and body size. Ethology 103:369-383

Hixon MA, Beets JP (1993) Predation, prey refuges, and the structure of coral-reef fish assemblages. Ecol Monogr 63:77-101

Johnson DW (2006) Density dependence in marine fish populations revealed at small and large spatial scales. Ecology 87:319-325

Karino K, Kuwamura T (1997) Plasticity in spawning visits of female damselfish, Stegastes nigricans: effect of distance to mates. Behav Ecol Sociobiol 41:55-59

Knapp RA (1995) Influence of energy reserves on the expression of a secondary sexual trait in male bicolor damselfish, Stegastes partitus. Bull Mar Sci 57:672-681

Knapp RA, Warner RR (1991) Male parental care and female choice in the bicolor damselfish, Stegastes partitus: bigger is not always better. Anim Behav 41:747-756

Lindholm JB, Auster PJ, Kaufman LS (1999) Habitat-mediated survivorship of juvenile (0-year) Atlantic cod Gadus morhua. Mar Ecol Prog Ser 180:247-255

Lombardi L, Fernandez N, Moreno S, Villafuerte R (2003) Habitat-related differences in rabbit (Oryctolagus cuniculus) abundance, distribution, and activity J Mamm 84:26-36

Luckhurst BE, Luckhurst KL (1978) Analysis of the influence of substrate variables on coral reef fish communities. Mar Biol 49:317-323

Lyman SJ (2002) Reproductive behavior and demographic variability in the bicolor damselfish Stegastes partitus. PhD dissertation, Duke University, Durham, NC

Main KL (1987) Predator avoidance in seagrass meadows: prey behavior, microhabitat selection, and cryptic coloration. Ecology 68:170-180

Mandelik Y, Jones M, Dayan T (2003) Structurally complex habitat and sensory adaptations mediate the behavioural responses of a desert rodent to an indirect cue for increased predation risk. Evol Ecol Res 5:501-515

Mann DA, Lobel PS (1998) Acoustic behavior of the damselfish Dascyllus albisella: behavioral and geographic variation. Environ Biol Fish 51:421-428

McGehee MA (1995) Juvenile settlement, survivorship and in situ growth rates of four species of Caribbean damselfishes in the genus Stegastes. Environ Biol Fish 44:393-401

Meadows DW (2001) Center-edge differences in behaviour, territory size and fitness in clusters of territorial damselfish: patterns, causes and consequences. Behaviour 138:1085-1116

Myrberg AA (1972) Ethology of the bicolor damselfish, Eupomacentrus partitus (Pisces: Pomacentridae): a comparative analysis of laboratory and field behavior. Anim Behav Monogr 5:197-283

Myrberg AA (1997) Sound production by a coral reef fish (Pomacentrus partitus): evidence for a vocal, territorial 'keep-out' signal. Bull Mar Sci 60:1017-1025

Nemeth RS (1998) The effect of natural variation in substrate architecture on the survival of juvenile bicolor damselfish. Environ Biol Fish 53:129-141

Olsson O, Brown JS, Smith HG (2002) Long- and short-term state-dependent foraging under predation risk: an indication of habitat quality. Anim Behav 63:981-989

Robertson DR, Green DG, Victor BC (1988) Temporal coupling of production and recruitment of larvae of a Caribbean reef fish. Ecology 69:370-381

Sale PF (1980) The ecology of fishes on coral reefs. Oceanogr Mar Biol 18:367-331

Schmale MC (1981) Sexual selection and reproductive success in males of the bicolor damselfish, Eupomacentrus partitus, (Pisces: Pomacentridae). Anim Behav 29:1172-1184

Syms C, Jones GP (2001) Soft corals exert no direct effects on coral reef fish assemblages. Oecologia 127:560-571 